\title{
The heat is on
}

\section{Decarbonization of heat is a difficult challenge - with many interdependent factors - but one that is increasingly urgent for energy researchers to tackle.}

At this time of year, watching the browning leaves rustling in the cold wind, adjusting the set-points of thermostats in our homes and offices, it's easy for thoughts to turn to the issue of heating and its energy demands. In the UK, heating and hot water for buildings account for about $40 \%$ of energy consumption, with space heating making up about half of that ${ }^{1}$. Across the EU, half of final energy consumption can be attributed to heating and cooling ${ }^{2}$. In the US, $65 \%$ of household energy consumption goes on space heating, water heating, and air conditioning ${ }^{3}$. And this is without considering the energy needed by the industrial sector for heating. Indeed, the International Energy Agency reports that $50 \%$ of final energy consumption globally is used in the production of heat ${ }^{4}$. Currently, fossil fuels provide around 75\% of this energy, meaning heat is responsible for a significant proportion of greenhouse gas emissions. For many nations, tackling the decarbonization of heat is going to be essential to meeting climate obligations. Yet doing so presents a number of critical energy challenges with few simple answers.

Demand reduction is one obvious starting point. Cutting down on our need for heat or on our need for energy for heat - will help meet targets. Energy efficiency standards in heating appliances will be important here, as will standards for new buildings. But with the majority of buildings being old and their turnover being slow, renovation of existing buildings requires great attention. The EU's energy efficiency directive introduced measures for building renovations for member states. In its recent assessment of strategies for building renovations $s^{5}, 23$ out of 31 strategies met the requirements of establishing a long-term strategy beyond 2020 to mobilize investment in energy efficiency renovations for commercial and residential buildings. Hopefully this figure will rise to include all states by the next assessment in 2017. It will be even more important to understand the actual impact these strategies have on energy consumption and the rate at which renovations can be implemented in all sectors.

Beyond demand reduction, it is also essential to consider the modes by which we generate and distribute heat: electricity, gas, and heat itself. Electrification of heat is a tempting option. Electrified options like heat pumps are already in use and their further adoption - assuming we learn from the problems many consumers face with them - could be encouraged, especially in regions without gas networks. However, electrification of heat is not an end in itself. Bearing in mind the current energy demand for heating, any large-scale electrification will create substantial increases in electricity demand, which must be met by low-carbon or zero-carbon sources if it's going to achieve a drop in greenhouse gas emissions. This is no mean feat, especially in parallel with the extra electricity needed for electrified transport and any additional growth in overall demand.

Gas networks also appear promising. While they have a lower penetration than electricity networks, they still cover large areas in most developed nations. Repurposing them to carry lower-carbon forms of gas, like biomethane or hydrogen, would make good use of existing infrastructure and avoids the networks becoming stranded assets. However, biomethane availability is not widespread. In the UK, for instance, it is currently estimated that biomethane could provide just $10 \%$ of domestic gas demand by $2035^{6}$.

Greater decarbonization could be achieved by considering hydrogen as an alternative energy vector. This journal has discussed the potential use of hydrogen before ${ }^{7}$. However, generating hydrogen currently remains costly and the processes are not without their climate risks. Steam methane reforming is widely used in industry but requires carbon capture and storage technologies to remove emissions. A more environmentally-friendly option is electrolysis: with efficient hydrogen storage, electrolysis could provide a potential solution for the intermittency problem of renewables by using them as a source during periods of low demand but high supply. However, as with electrification, this route to hydrogen generation calls for more electricity capacity, placing further strain on those networks. Photocatalytic hydrogen production would help, but cost-effective generation at the necessary scale is perhaps too far off to consider on the timescales needed at this stage.

Finally, heat networks have had success in some regions, notably Denmark, and warrant further consideration. They can be highly efficient, especially where they make use of waste heat from industrial processes or other power plants, and they can make use of a variety of fuels. However, they still depend on other fuel networks and have high capital costs to set up. While they may be attractive in localized regions, their large-scale deployment appears uncertain at present.

These three networks will also need to consider their societal impacts carefully. Considering the need for changes to technologies and practices alone, without considering the large upfront investments needed at both household and community levels, there is likely to be resistance to any changes in heat provision. Although some of this resistance can be viewed as system inertia that will change in time - with users having no preference over their heating appliances, just repairing or replacing what they already have - there is arguably an obligation to clearly communicate the need for substantive change, have engagement with it from users, and provide education on new appliances if change is to be successfully implemented. There are also many jobs in heating services that could be become obsolete if retraining is not provided.

Decarbonizing heat is a complex task with many interdependent factors and challenges for the energy sector. There is no one-sizefits-all approach: we will need to consider a suite of options at local, regional and national scales that consider different interannual time scales, adapting existing networks or building new ones where it makes most sense to. Major infrastructure investments are going to be required, whichever option is chosen, which means careful planning and policy are required. What is clear, however, is that more research and testing of different schemes are urgently needed if we are going to find solutions in sufficient time to meet our climate obligations.

\footnotetext{
References

1. Energy Consumption in the UK (Department for Business, Energy and Industrial Strategy, 2016).

2. An EU Strategy on Heating and Cooling (European Commission, 2016).

3. Residential Energy Consumption Survey 2009 (EIA, accessed 18 November 2016); http://go.nature.com/2flllwT

4. Eisentraut, A. \& Brown, A. Heating Without Global Warming: Market Developments and Policy Considerations for Renewable Heat (IEA, 2014).

5. Castellazzi, L., Zangheri, P. \& Paci, D. Synthesis Report on the Assessment of Member States' Building Renovation Strategies (European Commission, 2016).

6. The Decarbonisation of Heat (Ofgem, 2016).

7. Nat. Energy 1, 16127 (2016).
} 